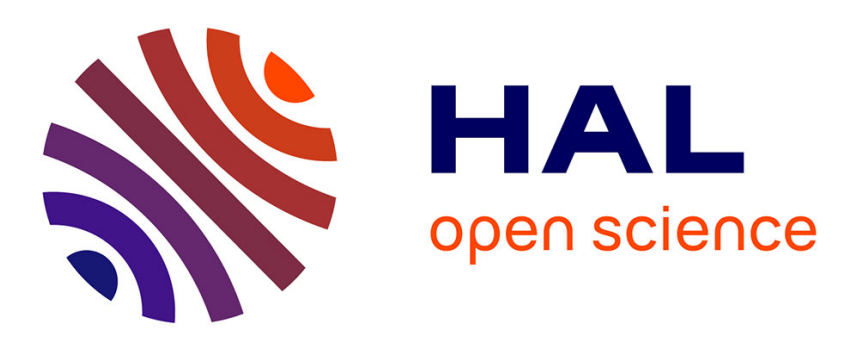

\title{
Application of Multiple Scattering in Platinum Based Heterogeneous Catalysts
}

\author{
Dominique Bazin, A. Bensaddik, H. Dexpert, J. Lynch
}

\section{To cite this version:}

Dominique Bazin, A. Bensaddik, H. Dexpert, J. Lynch. Application of Multiple Scattering in Platinum Based Heterogeneous Catalysts. Journal de Physique IV Proceedings, 1996, 06 (C4), pp.C4-487-C4491. 10.1051/jp4:1996446 . jpa-00254329

\section{HAL Id: jpa-00254329 https://hal.science/jpa-00254329}

Submitted on 1 Jan 1996

HAL is a multi-disciplinary open access archive for the deposit and dissemination of scientific research documents, whether they are published or not. The documents may come from teaching and research institutions in France or abroad, or from public or private research centers.
L'archive ouverte pluridisciplinaire HAL, est destinée au dépôt et à la diffusion de documents scientifiques de niveau recherche, publiés ou non, émanant des établissements d'enseignement et de recherche français ou étrangers, des laboratoires publics ou privés. 


\section{Application of Multiple Scattering in Platinum Based Heterogeneous Catalysts}

D. Bazin, A. Bensaddik, H. Dexpert and J. Lynch*

LURE, Bât. 209D, Université Paris-Sud, 91405 Orsay, France

* Institut Français du Pétrole, BP. 311, 92506 Rueil-Malmaison, France

Résumé : Jusqu'à présent, dans le domaine de la catalyse hétérogène, l'analyse des données de spectroscopie d'absorption X était partielle. En effet, le formalisme théorique associée ne prenait en compte que les processus de diffusion simple du photoelectron. La prise en compte des processus de diffusion multiple de $\propto$ photoelectron est désormais rendu possible grâce à l'avènement de codes de calcul fiables. Elle permet une modélisation bien plus fine de la structure cristallographique du matériau. L'étude du processus d'imprégnation du platine sur l'alumine vient ici illustrer notre propos.

Abstract : Up to now, Exafs analysis of heterogeneous catalysts has been made using the free electron single scattering model. Coordination numbers and interatomic distances were extracted according to the classical Exafs formula which relates modulations of the absorption coefficient and structural parameters. In this work, we try to consider multiple scattering in the analytical procedure in order to obtain a more precise structural description of the material at the first step of the preparation i.e. the impregnation-drying.

\section{INTRODUCTION}

Exafs spectroscopy is very important for the characterisation of catalysts as shown by the numerous works already published. One of the reasons is that this technique is able to provide an accurate picture of the metallic part during the preparation procedure as well as for the activation under in situ conditions. In this work, we try to complete the conventional analytical procedure based on the classical formula (plane wave single scattering approximation) [1] by a multiple scattering approach in order to improve our knowledge on the structural characteristics of the material at the impregnation-drying step.

\section{THE REFERENCE COMPOUNDS : $\mathrm{H}_{2}$ PTCL $_{6}$ AND $\left(\mathrm{NH}_{4}\right)_{3}$ IRCL $_{6}$}

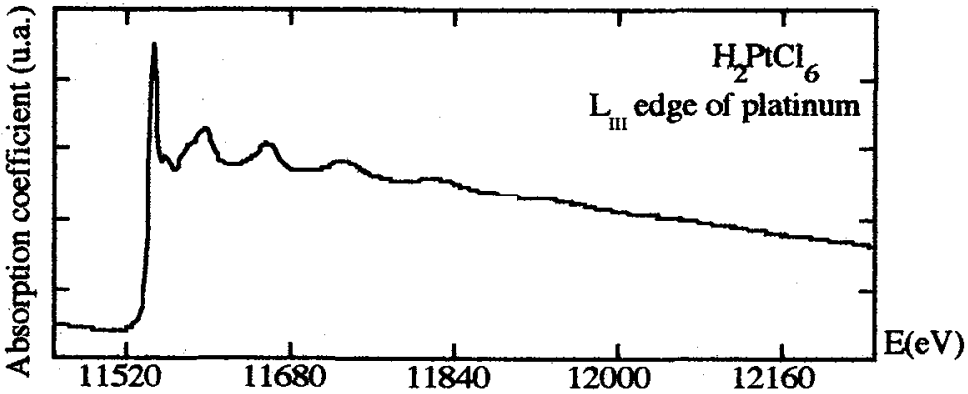

Figure 1 : Absorption spectrum of the compound $\mathrm{H}_{2} \mathrm{PtCl}_{6}$ taken at the $\mathrm{L}_{\mathrm{II}}$ edge of platinum.

Figure 1 : Spectre d'absorption du compose $\mathrm{H}_{2} \mathrm{PtCl}_{6}$ pris au seuil $\mathrm{L}_{\mathrm{III}}$ du platine. 


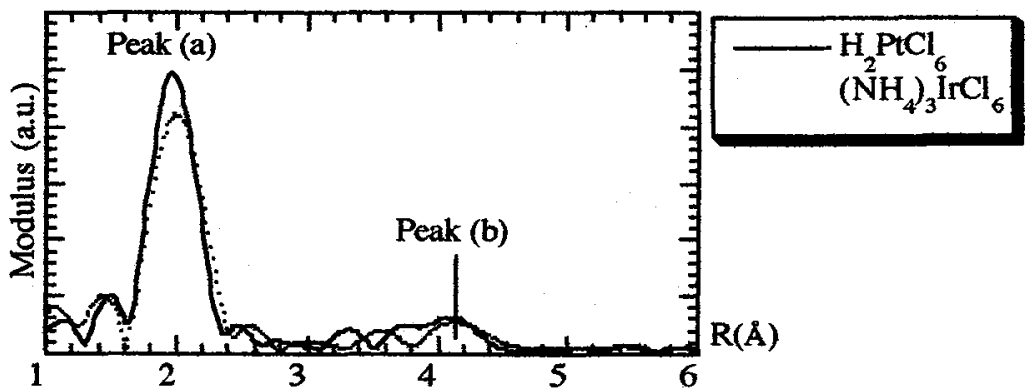

Figure 2 : Modulus of the two different reference compounds $\mathrm{H}_{2} \mathrm{PtCl}_{6}$ (line) et $\left(\mathrm{NH}_{4}\right)_{3} \mathrm{IrCl}_{6}$ (dots). Figure 2 : Modules de la transformée de Fourier associés à $\mathrm{H}_{2} \mathrm{PtCl}_{6}$ (continue) et $\left(\mathrm{NH}_{4}\right)_{3} \mathrm{IrCl}_{6}$ (pointilles).

A classical analytical procedure is basically a Fourier transform of the Exafs function using a Hanning type window [2]. Figure 1 shows the excellent signal to noise ratio associated to the absorption spectrum of the $\mathrm{H}_{2} \mathrm{PtCl}_{6}$ compound taken at the $\mathrm{Pt} \mathrm{LII}$ edge. It is well known that in such compounds where the metal is surrounded by a chlorine cage composed of six atoms at $2.32 \AA$, a small contribution (peak (b) in figure 2) appears in the modulus of the Fourier transform after the major one (peak (a) in figure 2) corresponding to the chlorine atoms [2]. Considering the first spectrum of the $\left(\mathrm{NH}_{4}\right)_{3} \mathrm{IrCl}_{6}$ compound measured in solution and using the FEFF 5 code [3], we started a new analysis of this spectra comparing the imaginary part of the Fourier transform associated with the experimental spectrum and those related to numerical simulations. In fact, to check the validity of the procedure, three simulations have been done which differ for example in the iridium sample by the IrCl interatomic distances (respectively equal to

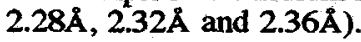

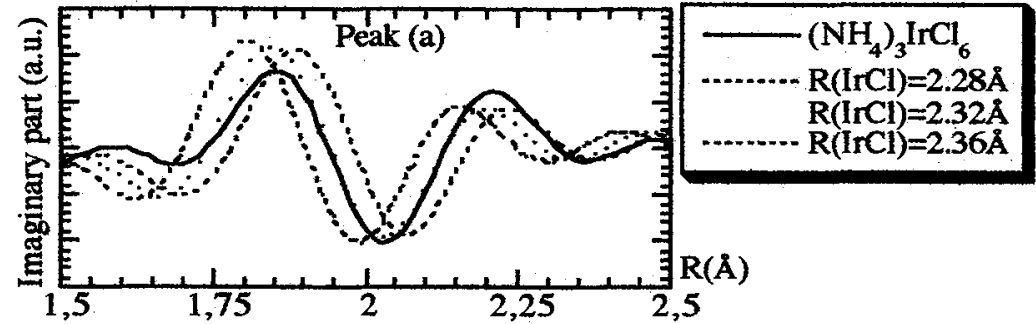

Figure 3 : Imaginary part of the Fourier transform of simulation (dots) and experimental data (line) for the refereace compound $\left(\mathrm{NH}_{4}\right)_{3} \mathrm{IrCl}_{6}$.

Figure 3 : Partie imaginaire de la transformé de Fourier du composé $\left(\mathrm{NH}_{4}\right)_{3} \mathrm{IrCl}_{6}$ (pointillés) et de certaines simulations théoriques (continue).

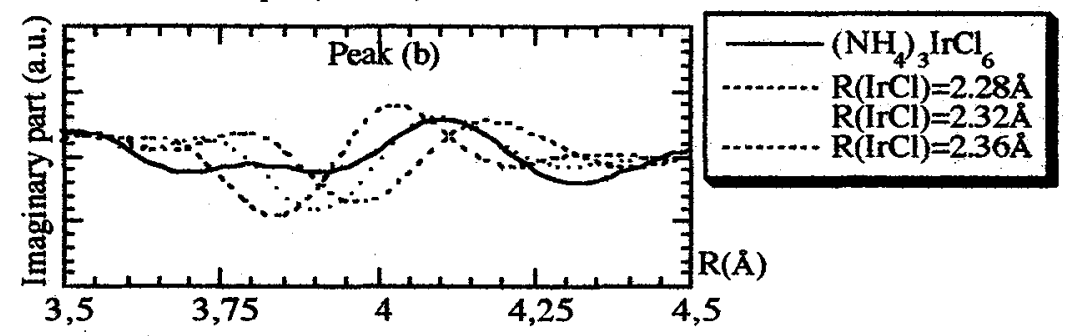

Figure 4 : Imaginary part of the Fourier transform of simulation (dots) and experimental data (line) for the reference compound $\left(\mathrm{NH}_{4}\right)_{3} \mathrm{IrCl}_{6}$.

Figure 4 : Partie imaginaire de la transformé de Fourier de $\left(\mathrm{NH}_{4}\right)_{3} \mathrm{IrCl}_{6}$ (pointillés) et de certaines simulations theoriques (continue). 
Figure 3 and 4 show clearly that the best agreement for peak (a) and (b) is obtained for an interatomic distance equal to $2.32 \AA$, a value in line with the crystallographic one. We recall here that ,up to now, no "agreement factor" for multiple scattering process has been defined.

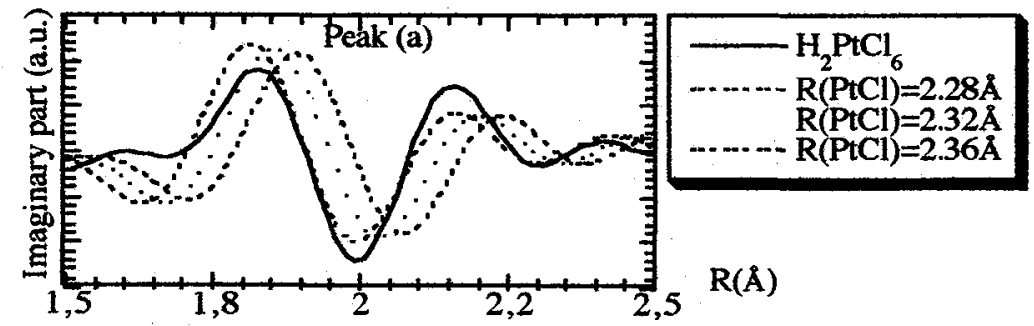

Figure 5 : Imaginary part of the Fourier transform of simulation (dots) and experimental data (line) for the reference compound $\mathrm{H}_{2} \mathrm{PtCl}_{6}$.

Figure 5 : Partie imaginaire de la transformée de Fourier du composé $\mathrm{H}_{2} \mathrm{PtCl}_{6}$ (continue) et de certaines simulations theoriques (pointilles).

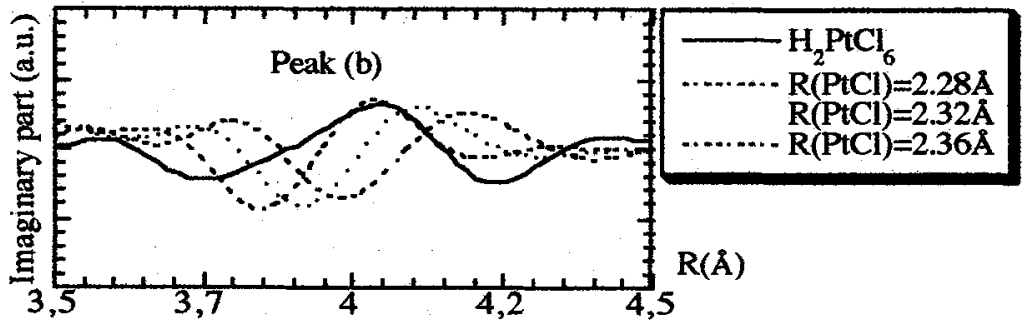

Figure 6 : Imaginary part of the Fourier transform of simulation (dots) and experimental data (line) for the reference compound $\mathrm{H}_{2} \mathrm{PtCl}_{6}$.

Figure 6 : Partie imaginaire de la transformée de Fourier du composé $\mathrm{H}_{2} \mathrm{PtCl}_{6}$ (continue) et de certaines simulations théoriques (pointilles).

We have also considered the spectrum of the hexachloroplatinic acid and figure 5 and figure 6 reports the imaginary part of the Fourier transform associated with the experimental spectra as well as the numerical simulations (platinum-chlorine distances equal to $2.32 \AA, 2.30 \AA$ and $2.28 \AA$ ). The best agreement is given by an interatomic distance of $2.28 \AA$ between platinum and chlorine atoms (peak (a) and peak (b)). The key point of this study is that these simple calculations seem to show that this signal (peak (b)), either for platinum or iridium, is coming from multiple scattering process inside the octahedra and not from clustering of metal- $\mathrm{Cl}_{6}$ octahedra. This is thus important as we can, thereby, follow or at least estimate the degree of organisation of the cluster.

\section{Study of the dried step of the platinum on alumina system}

A direct application is given by the study of the impregnation step of the preparation procedure. The samples are highly dispersed platinum deposited on $\gamma$-alumina extrudates (BET surface area $240 \mathrm{~m}^{2} / \mathrm{g}$ ). The metal and halogen contents were determined by X-ray fluorescence $(1 \% \mathrm{Pt}, 1.2 \% \mathrm{Cl}$, percent weight). At this stage, hexachloroplatinic acid is used as a precursor. Thus, schematically, the platinum atoms are present at the open surface of the carrier in $\mathrm{PtCl}_{6}$ entities. Exafs spectra were collected at the LURE synchrotron facility in Orsay using the synchrotron radiation from the DCI storage ring running at $1.85 \mathrm{GeV}$ with an average current of $300 \mathrm{~mA}$. The spectra were measured at the LIII edge of platinum for the monometallic and simultaneously at the platinum and rhenium $L_{\text {III }}$ edges for the bimetallic samples. The Exafs data were taken on the Exafs IV station through a double crystal monochromator (Si111), in the transmission mode and using two ionisation chambers as detectors. Calibration of the experiment was made with reference metal foils or compounds. 


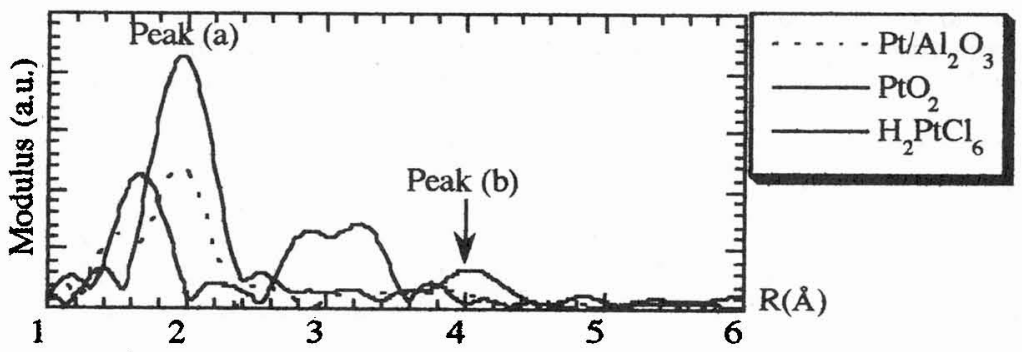

Figure 7 : Modulus of the impregnated sample (dots) compared to reference compounds $\mathrm{PtO}_{2}$ et $\mathrm{H}_{2} \mathrm{PtCl}_{6}$. Figure 7 : Modules de la transformée de Fourier de l'échantillon (pointillés) comparés aux deux composés de néference $\mathrm{PtO}_{2}$ et $\mathrm{H}_{2} \mathrm{PtCl}_{6}$.

In figure 7, as a reminder of a well known situation, we have compared the modulus of the Fourier transform associated with the sample with the modulus related to $\mathrm{PtO}_{2}$ and $\mathrm{H}_{2} \mathrm{PtCl}_{6}$. Basically, it is clear that platinum environment is made of oxygen and chlorine atoms. Following the classical analysis procedure (background removal, simulation of the atomic absorption using a polynomial function, extraction of the Exafs oscillation, Fourier transform of the Exafs oscillation), the fitting procedure gives on average 2.5 oxygen atoms at $1.98 \AA$ and 3.8 chlorine atoms at $2.30 \AA$ around platinum atoms.

Now, from the above considerations, we can try to complete this description. By considering the peak (b), it seems that this signal has completely vanished. We can consider two hypothesis to explain this fact. Firstly, platinum environment is a mixture of $\mathrm{PtCl}_{6}$ and $\mathrm{PtO}_{6}$ entities. Secondly, an unique kind of species, mixing chlorine and oxygen, exist inside the material as for example $\mathrm{PtCl}_{4} \mathrm{O}_{2}$. In the first case, peak (b) has to be present in the modulus associated to the sample with an amplitude related to the number of chlorine found by the fitting procedure. It seems that it is not the case, peak (b) having totally absent.

This fact is in line with the second hypothesis and thus the result is in favour of an entity which contains both chlorine and oxygen. A more accurate picture of the material is consequently obtained. Nevertheless, in order to clarify the situation, we have made different simulations with the FEFF 5 code corresponding to the situation where chlorine atoms at $2.32 \AA$ are replaced one by one by oxygen atoms at a distance of $2.04 \AA$.

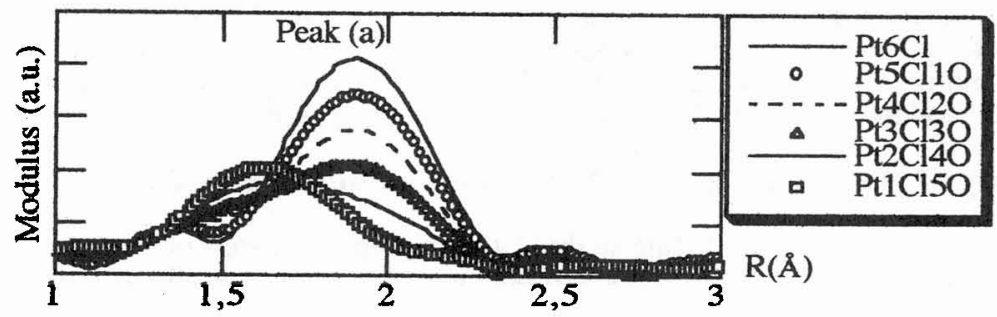

Figure 8 : Effect on the peak (a) of a substitution chlorine-oxygen in the first coordination sphere of the platinum atom

Figure 8 : effet sur le pic a d'une substitution chlore-oxygène dans l'environnement du platine. 


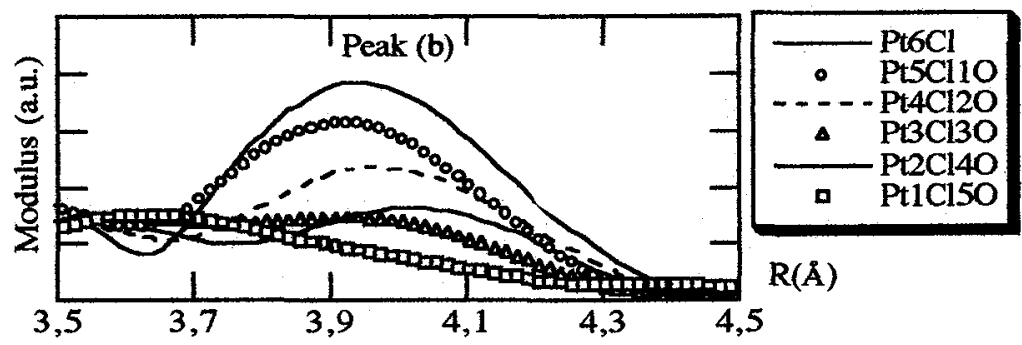

Figure 8 : Effect on the peak (b) of a substitution chlorine-oxygen in the first coordination sphere. Figure 8 : effet sur le pic b d'une substitution chlore-oxygène dans l'environnement du platine.

Figure 8 and figure 9 show the modulus corresponding to each kind of environment. The effect on peak (a) is clearly related to the backscattering phase and amplitude differences between chlorine and oxygen atoms. For peak (b), it seems that only a significant substitution of chlorine by oxygen atoms in the vicinity of platinum destroys the peak (b). Thus, the octahedra symmetry around the platinum atom is highly disturbed, this loss of symmetry inducing a significant decrease of the intensity of the peak (b). Work is in progress to simulate such distortion around the metal atom.

\section{CONCLUSION}

We have shown that a multiple scattering approach is necessary for the characterisation of heterogeneous catalysts in order to obtain a clear structural determination. At the impregnation-drying step, we have shown that such analysis gives more information on the nature of the process and the entities deposited at the surface of the carrier. It shows that we can finally distinguish between a mixture of $\mathrm{PtO}_{2}$ and $\mathrm{PtCl}_{6}$ entities and a single species like $\mathrm{PtO}_{\mathrm{x}} \mathrm{Cl}_{\mathrm{y}}$. Work is in progress to apply the same approach to the calcination and the reduced steps.

\footnotetext{
References

[1] LYTLE F. W., SAYERS D. E., STERN E. A., Phys. Rev. B11, 4825 (1975).

[2] BAZIN D., DEXPERT H., BOURNONVILLE J. P., LAGARDE P., J. Cat. 110,209(1988).

[3] REHR J. J., ALBERS R. C., Phys. Rev. B41, 8149(1990).
} 